\title{
Active and Passive Components of Chloride Transport in the Rat Proximal Convoluted Tubule
}

\author{
Robert J. Alpern, Kenneth J. Howlin, and Patricia A. Preisig \\ With the technical assistance of Kenneth R. Wong \\ Departments of Medicine and Physiological Nursing and the Cardiovascular Research Institute, \\ University of California, San Francisco, California 94143
}

\begin{abstract}
Rat proximal convoluted tubules were perfused in vivo to examine the active and passive components of chloride absorption. Chloride flux was a linear function of the transepithelial electrochemical driving force, yielding a permeability coefficient of $\mathbf{2 0 . 6}$ $\times 10^{-5} \mathrm{~cm} / \mathrm{s}$. In the absence of an electrochemical driving force, chloride absorption persisted at the rate of $131 \mathrm{peq} / \mathrm{mm} \cdot \mathrm{min}$, thus demonstrating active absorption of chloride. Addition of luminal cyanide to tubules absorbing chloride inhibited net chloride absorption. In tubules perfused with a low luminal chloride concentration in which there was net chloride secretion, addition of luminal cyanide increased the magnitude of net chloride secretion. These studies demonstrate that transepithelial chloride transport involves two components: a passive paracellular flux and an active transcellular flux. Cyanide affects net chloride flux by inhibiting active transcellular chloride absorption.
\end{abstract}

\section{Introduction}

Volume absorption in rat proximal convoluted tubules (PCT) ${ }^{1}$ occurs in two phases. In the first phase, the absorption of organic solutes (glucose, amino acids, and organic acids) and bicarbonate accounts for most of the volume absorption and is associated with a rise in luminal chloride concentration. The second phase occurs from a tubular fluid high in chloride, low in bicarbonate, and virtually free of organics, and involves mostly $\mathrm{NaCl}$ absorption. The question of what the mechanism is by which the PCT of the rat kidney performs this $\mathrm{NaCl}$ absorption remains unresolved.

Neumann and Rector (1) found that chloride absorption in this second phase was critically dependent on a high luminal chloride concentration and on a favorable electrochemical gradient. In tubules perfused with a solution in which absorbable organic solutes were replaced by raffinose, and in which $20 \mathrm{mM}$ $\mathrm{NaHCO}_{3}$ was replaced by an equivalent amount of a nonabsorbable anion (cyclamate, sulfate, and methylsulfate), there was no rise in luminal chloride concentration, and the rate of volume absorption was close to zero. These results have been subsequently confirmed by Green et al. (2), and confirmed also in

Address reprint requests and correspondence to Dr. Alpern, Division of Nephrology, 1065 HSE. 1985.

Received for publication 10 August 1984 and in revised form 6 May

1. Abbreviations used in this paper: PCT, proximal convoluted tubule; PD, potential difference.

J. Clin. Invest.

(c) The American Society for Clinical Investigation, Inc.

0021-9738/85/10/1360/07 \$1.00

Volume 76, October 1985, 1360-1366 the superficial rabbit PCT by Jacobson (3). Chantrelle et al. (4) found similar results when acetazolamide was added to make bicarbonate nonabsorbable and thus prevent the luminal chloride concentration from rising. From these results it was concluded that chloride absorption is totally passive and dependent on a favorable electrochemical gradient.

Frömter et al. (5) came to a similar conclusion using the split droplet technique. These authors changed luminal or peritubular $\mathrm{NaCl}$ concentration by raffinose replacement, and concluded that chloride absorption was totally passive with onehalf due to diffusion and one-half due to solvent drag.

Other studies, however, have found that a fraction of chloride transport is dependent on active transport. This fraction of chloride absorption has been found to be inhibitable by cyanide, luminal SITS (4-acetamido-4'-isothiocyanostilbene-2,2'-disulfonate), luminal furosemide, luminal and peritubular potassium removal, and cooling $(2,6-8)$. These results suggest that a significant fraction of chloride absorption from late proximal tubular fluid is dependent on the presence of active transport.

Three possibilities could explain these results. The first is that the absence of chloride absorption when bicarbonate is replaced by cyclamate, sulfate, or methylsulfate (1-3) is due to inhibition of a luminal membrane chloride transport system by the nonabsorbable anions rather than to changes in the electrochemical driving force for chloride. Second, it is possible that inhibitors such as cyanide, potassium removal, or cooling cause cell swelling, which causes the lateral intercellular space to become smaller and secondarily decreases paracellular chloride permeability. Lastly, it is possible that chloride transport is entirely passive and paracellular, yet dependent on active transcellular sodium transport. This last possibility could occur if active transport of sodium generated the electrochemical driving force for passive chloride diffusion (i.e., the transepithelial potential difference [PD] and/or the high luminal chloride concentration). This would explain both the dependence of chloride absorption on a favorable electrochemical gradient and the reduction of chloride transport when active transport is inhibited.

The present studies were designed, therefore, to further examine the effect of the transepithelial electrochemical gradient and metabolic inhibition on the rate of chloride absorption. The results demonstrate that transepithelial chloride transport includes two components, a passive paracellular flux with an apparent permeability coefficient of $20.6 \times 10^{-5} \mathrm{~cm} / \mathrm{s}$ and an active transcellular flux equal to $100-160 \mathrm{peq} / \mathrm{mm} \cdot \mathrm{min}$. In addition, it is demonstrated that cyanide inhibits chloride absorption by inhibiting active transcellular chloride absorption, and not by effects on the chloride permeability.

\section{Methods}

Experiments were performed using male Wistar rats (Charles River Breeding Laboratories, Wilmington, MA) weighing 200-298 g. The rats 
Table I. Perfusion Solutions for Chloride Flux Studies

\begin{tabular}{|c|c|c|c|c|c|c|c|c|c|c|}
\hline & 1 & 2 & 3 & 4 & 5 & 6 & 7 & 8 & 9 & 10 \\
\hline & $m M$ & $m M$ & $m M$ & $m M$ & $m M$ & $m M$ & $m M$ & $m M$ & $m M$ & $m M$ \\
\hline $\mathrm{NaCl}$ & 140 & 100 & 120 & 80 & 140 & 140 & 95 & 95 & 45 & 45 \\
\hline $\mathrm{NaHCO}_{3}$ & 5 & 5 & 25 & 25 & 5 & 5 & 5 & 5 & 5 & 5 \\
\hline $\mathrm{KCl}$ & 5 & 5 & 5 & 5 & 5 & 5 & 5 & 5 & 5 & 5 \\
\hline $\mathrm{MgSO}_{4}$ & 1 & 1 & 1 & 1 & 1 & 1 & 1 & 1 & 1 & 1 \\
\hline $\mathrm{CaCl}_{2}$ & 1.8 & 1.8 & 1.8 & 1.8 & 1.8 & 1.8 & 1.8 & 1.8 & 1.8 & 1.8 \\
\hline $\mathrm{Na}_{2} \mathrm{HPO}_{4}$ & 1 & 1 & 1 & 1 & 1 & - & 1 & - & 1 & - \\
\hline Na-Isethionate & - & - & - & - & 8.5 & - & 8.5 & - & 8.5 & - \\
\hline Glucose & 5 & 5 & 5 & 5 & - & - & - & - & - & - \\
\hline Alanine & 5 & 5 & 5 & 5 & - & - & - & - & - & - \\
\hline Urea & 5 & 5 & 5 & 5 & - & - & - & - & - & - \\
\hline Raffinose & - & 63 & - & 63 & - & - & 80 & 80 & 170 & 170 \\
\hline $\mathrm{NaCN}$ & - & - & - & - & - & 10 & - & 10 & - & 10 \\
\hline
\end{tabular}

were prepared for microperfusion as previously described (9). Throughout the experiment, rats were infused intravenously with a bicarbonate Ringer's solution (105 mM NaCl, $25 \mathrm{mM} \mathrm{NaHCO}_{3}, 4 \mathrm{mM} \mathrm{Na}_{2} \mathrm{HPO}_{4}$, $5 \mathrm{mM} \mathrm{KCl}, 1 \mathrm{mM} \mathrm{MgSO}_{4}, 1.8 \mathrm{mM} \mathrm{CaCl}_{2}$ ) at $1.6 \mathrm{ml} / \mathrm{h}$. Proximal tubular transit time was measured after injection of $0.02 \mathrm{ml}$ of $10 \%$ lissamine green dye intravenously; only those kidneys in which transit time was $<12 \mathrm{~s}$ were accepted for study.

After completion of surgery, rat PCTs were microperfused as previously described (9), using a thermally insulated microperfusion pump (Wolfgang Hampel, Berlin, Federal Republic of Germany). A perfusion pipette was placed into a proximal loop. An oil block was placed proximal to the perfusion pipette and a hole was left for glomerular ultrafiltrate to escape.

In the studies in which chloride flux was measured, tubules were perfused at $16 \mathrm{nl} / \mathrm{min}$, a collection pipette placed in a late proximal loop, an oil block inserted distally, and a timed collection made. After the collection, the tubule was filled with microfil (Canton Biomedical Products, Boulder, $\mathrm{CO}$ ). On a subsequent day the kidney was incubated in 6 $\mathrm{N} \mathrm{HCl}$ at $37^{\circ} \mathrm{C}$ for $60 \mathrm{~min}$, allowing dissection of the microfil cast and measurement of the perfused length. Tubules were only accepted that were $\geq 1 \mathrm{~mm}$ in length.

In studies in which PD was measured, tubules were perfused at 40 $\mathrm{nl} / \mathrm{min}$. With the microelectrode in superfusate (see Table II) above the kidney, the electrometer was set to zero. The microelectrode then was placed into the tubule one loop distal to the perfusion pipette. The intraluminal position of the microelectrode was confirmed by the spontaneous influx of colored perfusate (fluid in perfusion pipettes contained FD and $C$ green dye [see below]). Elevation of a fluid chamber connected to the microelectrode (see below) enabled further influx to be arrested. Only studies in which the PD had been stable within $0.1 \mathrm{mV}$ for at least 1 min were accepted. Afterwards, the electrode was withdrawn and the postpuncture $P D$ in the superfusate recorded for $1 \mathrm{~min}$. If the postpuncture PD did not rapidly return to and stabilize within $0.1 \mathrm{mV}$ of the prepuncture PD, the measurement was not accepted.

The perfusion solutions used in the chloride flux studies are listed in Table I, and those used in the electrical studies are listed in Table II. The solutions used in the electrical studies were designed to approximate the mean luminal concentrations of $\mathrm{NaCl}$ and $\mathrm{NaHCO}_{3}$ of the respecive perfusion solutions in Table I. ${ }^{2}$ All perfusion solutions were gassed with $90 \% \mathrm{O}_{2} / 10 \% \mathrm{CO}_{2}$ and contained $0.05 \%$ FD and $\mathrm{C}$ green dye No. 3. Perfusates used to measure chloride flux also contained exhaustively dialyzed methoxy- ${ }^{3} \mathrm{H}$-inulin. In the chloride flux studies, the kidney was covered with oil warmed to $37^{\circ} \mathrm{C}$ and equilibrated with $90 \%$

2. We have measured the collected bicarbonate concentrations in these studies and have reported the results elsewhere (10).
$\mathrm{O}_{2} / 10 \% \mathrm{CO}_{2}$. In the electrical studies, the kidney was bathed in superfusate (Table II), which was also warmed to $37^{\circ} \mathrm{C}$ and equilibrated with $90 \%$ $\mathrm{O}_{2} / 10 \% \mathrm{CO}_{2}$.

Analysis-flux studies. Perfusate and collected samples were covered with Hepes equilibrated paraffin oil, bubbled with $10 \% \mathrm{CO}_{2}$ (9). The samples were transferred into constant bore tubing for measurement of collected volume. A 1-2-nl aliquot was then removed for determination of chloride concentration, and the remaining fluid was transferred to a vial for liquid scintillation counting as previously described (9). Chloride concentration was measured in perfused and collected fluid by the microtitrimetric method of Ramsay et al. (11), and in plasma and perfusion fluid titrimetrically (Buchler-Cotlove chloridometer, Buchler Instruments, Inc., Fort Lee, NJ).

In pilot studies, we found that the microtitrimetric method titrated cyanide on an equimolar basis relative to chloride, whereas the macromethod did not. Therefore, in the cyanide studies, the results of the macro-measurements were used for the perfusion fluid. For the collected fluid, we were only able to use the results of the microtitrimetric method, but corrected these by subtracting $2 \mathrm{meq} / \mathrm{liter}$ from the measured results. The subtracted value was based on previous results from our laboratory, which found that when $8.3 \mathrm{meq} / \mathrm{liter}$ sodium cyanide was perfused into the PCT at $15.3 \mathrm{nl} / \mathrm{min}$, collected cyanide concentration was $1.6 \pm 0.1$ $\mathrm{meq} /$ liter in tubules averaging $2.0 \pm 0.2 \mathrm{~mm}$ in length $(n=10)(12)$. Small errors in this correction will have minimal effects on the results.

Analysis-potential difference studies. Measurements of the transepithelial PD were made by a technique similar to that described by Barratt et al. (13) and by Neumann and Rector (1). Microelectrodes were made

Table II. Perfusion Solutions for PD Studies

\begin{tabular}{|c|c|c|c|c|c|}
\hline & $1 \mathrm{~A}$ & $2 \mathrm{~A}$ & $3 \mathrm{~A}$ & $4 \mathrm{~A}$ & Superfusate \\
\hline & $m M$ & $m M$ & $m M$ & $m M$ & $m M$ \\
\hline $\mathrm{NaCl}$ & 136 & 100 & 123 & 84 & 105 \\
\hline $\mathrm{NaHCO}_{3}$ & 5 & 5 & 18 & 19 & 25 \\
\hline $\mathrm{KCl}$ & 5 & 5 & 5 & 5 & 5 \\
\hline $\mathrm{MgSO}_{4}$ & 1 & 1 & 1 & 1 & 1 \\
\hline $\mathrm{CaCl}_{2}$ & 1.8 & 1.8 & 1.8 & 1.8 & 1.8 \\
\hline $\mathrm{Na}_{2} \mathrm{HPO}_{4}$ & 1 & 1 & 1 & 1 & - \\
\hline $\mathrm{Na}$-Isethionate & 4 & - & 4 & 2 & 15 \\
\hline Glucose & 5 & 5 & 5 & 5 & 5 \\
\hline Alanine & 5 & 5 & 5 & 5 & 5 \\
\hline Urea & 5 & 5 & 5 & 5 & 5 \\
\hline Raffinose & - & 63 & - & 63 & - \\
\hline
\end{tabular}


using glass pipettes with bevelled tips (3-5 $\mu \mathrm{m}$ OD), which were filled with the luminal perfusate. These were connected to a bridge containing the same fluid in series with a 3.6-M-KCl/0.9-M- $\mathrm{KNO}_{3}$ agarose bridge, which was then connected to a calomel half-cell. On the reference side of the circuit, the cut end of the rat's tail was placed in superfusate, which was connected via a 3.6-M-KCl/0.9-M-KNO ${ }_{3}$ agarose bridge to the reference calomel half-cell. A W.P.I. model F 223 dual electrometer (W.P.I. Instruments, Inc., New Haven, CT) connected the half-cells. Its output was recorded by a chart recorder (Electronik 194, Honeywell Inc., Fort Washington, PA), and measured to the nearest $0.05 \mathrm{mV}$. The movement of fluid into or out of the microelectrode could be controlled by adjusting the elevation of the fluid level in a feeding chamber that was in series with the microelectrode. To minimize tip-potential artifacts related to tubular puncture, we performed the experiments with the microelectrode filled with the luminal perfusion fluid. The electrometer was set to zero with the microelectrode in the superfusate on the surface of the kidney, and measured values were corrected for the liquid junction potential between the perfusion fluid and the superfusate (see below).

The electrical circuit when the electrometer is set to zero with the microelectrode in the superfusate is the following: calomel : $\mathrm{KCl}$ /

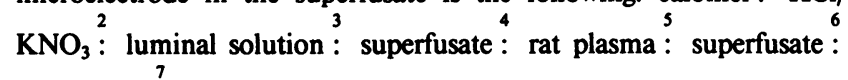
$\mathrm{KCl} / \mathrm{KNO}_{3}$ : calomel, where the numbers above the colons represent the junctions. The electrical circuit during measurements with the microelectrode in the tubular lumen is the following: calomel : $\mathrm{KCl}$ / $\mathrm{KNO}_{3}{ }^{2}$ : luminal solution : interstitial fluid: rat plasma : superfusate : ${ }^{6} \mathrm{KCl} / \mathrm{KNO}_{3}{ }^{7}$ : calomel. In both circuits, $E_{1}$ equals $-E_{7}$. In addition, since the superfusate was designed to be similar to a plasma ultrafiltrate, $E_{4}$ equals $-E_{5}$ in both circuits. Thus in the zeroing circuit the measured voltage $\left(E_{\text {zero }}\right)$ equals

$E_{\text {zero }}=E_{2}+E_{3}+E_{6}=0$,

and in the experimental circuit, the measured voltage $\left(E_{\text {exp }}\right)$ equals

$E_{\text {exp }}=E_{2}+E_{\text {tubule }}+E_{6}$.

The PD actually measured ( $\left.E_{\text {mees }}\right)$ will be the difference between the two voltages

$E_{\text {meas }}=E_{\text {exp }}-E_{\text {zero }}=E_{\text {tubule }}-E_{3}$.

Thus, to calculate the transepithelial PD $\left(E_{\text {tubule }}\right)$, the measured PD must be corrected by adding back $E_{3}$. To measure this liquid junction potential, we filled polyethylene tubing with perfusate and connected to it a calomel half-cell via a 3.6-M-KCl/0.9-M- $\mathrm{KNO}_{3}$ agarose bridge. This was then placed into a bath containing either perfusate (where the circuit was zeroed) or superfusate that was connected by a 3.6-M- $\mathrm{KCl} / 0.9-\mathrm{M}-\mathrm{KNO}_{3}$ agarose bridge to the reference calomel half-cell. The measured liquid junction potentials between the luminal perfusate and the superfusate are shown in Table III.

It should be noted that the transepithelial PD measured above $\left(E_{\text {tubule }}\right)$ will be the PD between the tubular lumen and the interstitial fluid. If driving forces are considered between these two compartments, this PD is used and the ultrafilterable chloride concentration must be used (plasma chloride concentration multiplied by the Donnan factor). If, on the other hand, one wishes to consider the driving forces between lumen and rat's plasma, the plasma chloride concentration can be used. However, the PD in this case equals the sum of $E_{\text {tubule }}$ and $E_{4}$ (the Donnan PD). Both of these approaches are identical in theory, and in practice lead to similar results. In the present manuscript, we have chosen to consider the driving forces between lumen and interstitium.

Calculations. The perfusion rate $\left(V_{\mathrm{o}}\right)$ was calculated as

$V_{\mathrm{O}}=\left(I_{L} / I_{\mathrm{O}}\right) V_{L}$,

where $I_{L}$ and $I_{O}$ represent the inulin concentration in the collected and perfused fluids, respectively, and $V_{L}$ is the collection rate. Volume flux $\left(J_{v}\right)$ was calculated as
Table III. Liquid Junction Potentials

\begin{tabular}{ll}
\hline Perfusate & PD \\
\hline & $m V$ \\
$1 \mathrm{~A}$ & +1.05 \\
$2 \mathrm{~A}$ & +0.30 \\
$3 \mathrm{~A}$ & +0.65 \\
$4 \mathrm{~A}$ & -0.45 \\
\hline
\end{tabular}

$J_{\mathrm{v}}=\left(V_{\mathrm{O}}-V_{L}\right) / L$,

where $L$ equals the perfused length.

Chloride flux $\left(J_{\mathrm{C}}\right)$ was calculated as

$J_{\mathrm{C}}=\left(C_{\mathrm{o}} V_{\mathrm{O}}-C_{L} V_{L}\right) / L$,

where $C_{\mathrm{O}}$ and $C_{L}$ represent the perfused and collected chloride concentrations, respectively. Mean luminal chloride concentration $\left(\bar{C}_{L}\right)$ was calculated using the arithmetic mean of the perfused and collected fluids:

$\bar{C}_{L}=\left(C_{\mathrm{o}}+C_{L}\right) / 2$.

Mean chloride concentration $(\bar{C})$ was calculated as the arithmetic mean of plasma ultrafiltrate $\left(C_{\mathrm{p}}\right)$ and mean luminal chloride concentration:

$\bar{C}=\left(C_{\mathrm{p}}+\bar{C}_{\mathrm{L}}\right) / 2$.

The electrochemical driving force for chloride $\left(D F_{\mathrm{C}}\right)$, in meq/liter, was calculated using the equation,

$D F_{\mathrm{C}}=\left(\overline{C_{L}}-C_{\mathrm{p}}\right)-(\bar{C} \mathrm{~F} \Delta V / \mathrm{RT})$,

where $\mathrm{F}$ is Faraday's constant, $\Delta V$ the measured transepithelial $\mathrm{PD}, \mathrm{R}$ the gas constant, and $\mathrm{T}$ the absolute temperature. An apparent chloride permeability was then calculated as the slope of a plot of chloride flux as a function of its electrochemical driving force. ${ }^{3}$

Linear regression analysis was performed by the least squares method. Data are presented as mean \pm SEM. Slopes and intercepts are reported \pm SD.

\section{Results}

The plasma chloride concentration was $101.8 \pm 0.8 \mathrm{meq} / \mathrm{liter}$ $(n=23)$. When corrected for a plasma water content of $94 \%$ and a Donnan factor of 1.05 , this plasma concentration gave an ultrafiltrate chloride concentration of $113.7 \mathrm{meq} / \mathrm{liter}$.

Chloride flux as a function of the electrochemical gradient. In the first series of studies, luminal chloride concentration was varied by replacing $\mathrm{NaCl}$ with either $\mathrm{NaHCO}_{3}$ or raffinose (perfusates 1-4, Table I). The results of these studies are shown in Table IV. In general, as mean luminal chloride concentration rose, the absorptive flux of chloride increased.

To examine the relationship between the electrochemical driving force and chloride flux, it was necessary to measure the transepithelial PD. However, in these studies, the luminal chloride and bicarbonate concentrations, and thus, the transepithelial $\mathrm{PD}$, change along the length of the tubule. To approximate the

3. The chloride permeability measured here is described as an apparent permeability because it is measured in the presence of volume flux. If there were no chloride-water interactions this would not be a problem. However, a number of studies have found solute-solvent interactions in the rat PCT $(5,10,14,15)$. If these were quantitatively important, the present measurements would be expected to overestimate the chloride permeability as compared with measurements using tracer chloride efflux in the absence of volume flux (see Discussion). 


\begin{tabular}{|c|c|c|c|c|c|c|c|c|}
\hline \multirow[b]{2}{*}{ Perfusate } & & \multirow[b]{2}{*}{ Length } & \multirow[b]{2}{*}{ Perfusion rate } & \multicolumn{3}{|c|}{ Chloride concentration } & \multirow[b]{2}{*}{ Volume flux } & \multirow[b]{2}{*}{ Chloride flux } \\
\hline & & & & Perfused & Collected & $\begin{array}{l}\text { Mean } \\
\text { luminal }\end{array}$ & & \\
\hline & $n$ & $m m$ & $\mathrm{nl} / \mathrm{min}$ & meq/liter & meq/liter & meq/liter & $\mathrm{nl} / \mathrm{mm} \cdot \min$ & $\mathrm{peq} / \mathrm{mm} \cdot \mathrm{min}$ \\
\hline 1 & 5 & $2.41 \pm 0.27$ & $16.76 \pm 0.18$ & $148.0 \pm 0.1$ & $142.0 \pm 2.8$ & $145.0 \pm 1.4$ & $2.15 \pm 0.17$ & $355 \pm 32$ \\
\hline 2 & 5 & $2.13 \pm 0.20$ & $16.32 \pm 0.41$ & $108.8 \pm 0.2$ & $107.3 \pm 3.5$ & $108.1 \pm 1.9$ & $-0.13 \pm 0.16$ & $-6 \pm 12$ \\
\hline 3 & 10 & $2.43 \pm 0.18$ & $17.28 \pm 0.20$ & $130.2 \pm 0.2$ & $131.7 \pm 1.4$ & $131.0 \pm 0.9$ & $2.18 \pm 0.10$ & $280 \pm 17$ \\
\hline 4 & 5 & $2.28 \pm 0.25$ & $15.30 \pm 0.60$ & $89.3 \pm 0.1$ & $96.3 \pm 2.2$ & $92.8 \pm 1.1$ & $-0.66 \pm 0.30$ & $-108 \pm 21$ \\
\hline 5 & 8 & $2.40 \pm 0.35$ & $17.13 \pm 0.51$ & $146.8 \pm 0.5$ & $140.5 \pm 3.2$ & $143.6 \pm 1.9$ & $2.03 \pm 0.24$ & $341 \pm 47$ \\
\hline 6 & 8 & $2.25 \pm 0.18$ & $15.55 \pm 0.57$ & $148.0 \pm 0.7$ & $133.4 \pm 3.2$ & $140.7 \pm 1.7$ & $0.69 \pm 0.11$ & $194 \pm 30$ \\
\hline 7 & 9 & $2.24 \pm 0.11$ & $16.28 \pm 0.61$ & $104.4 \pm 0.1$ & $112.2 \pm 1.3$ & $108.3 \pm 0.7$ & $-0.84 \pm 0.11$ & $-151 \pm 21$ \\
\hline 8 & 7 & $1.84 \pm 0.32$ & $16.23 \pm 0.71$ & $103.7 \pm 0.1$ & $106.7 \pm 1.8$ & $105.2 \pm 0.9$ & $-2.17 \pm 0.33$ & $-254 \pm 40$ \\
\hline 9 & 9 & $1.86 \pm 0.17$ & $16.72 \pm 0.46$ & $56.0 \pm 0.3$ & $70.4 \pm 2.2$ & $63.2 \pm 1.0$ & $-2.79 \pm 0.23$ & $-334 \pm 37$ \\
\hline 10 & 8 & $1.85 \pm 0.28$ & $16.01 \pm 0.48$ & $54.8 \pm 0.5$ & $78.5 \pm 2.1$ & $66.7 \pm 1.1$ & $-3.54 \pm 0.42$ & $-501 \pm 57$ \\
\hline
\end{tabular}

mean transepithelial PD, we therefore designed perfusion solutions that contained the mean luminal chloride and bicarbonate concentrations (Table II). These solutions were perfused at rapid rates, with a proximal block in place, and the PD was measured in the subsequent loop. The results are shown in Table V.

Fig. 1 shows the rates of chloride flux examined as a function of the electrochemical driving force. It can be seen that chloride flux is a linear function of the driving force. The slope of this line is $9.35 \pm 0.28 \mathrm{nl} / \mathrm{mm} \cdot \mathrm{min}$, which yields an apparent permeability coefficient of $20.6 \times 10^{-5} \mathrm{~cm} / \mathrm{s}$. In addition, it can be seen that the $y$-intercept is equal to $131 \pm 6 \mathrm{peq} / \mathrm{mm} \cdot \mathrm{min}$, a value significantly different from zero $(P<0.005)$. Thus, in the absence of an electrochemical driving force, chloride is absorbed at a rate of $131 \mathrm{peq} / \mathrm{mm} \cdot \mathrm{min}$.

Effect of cyanide on chloride absorption and secretion. The next set of studies was designed to examine the effect of metabolic inhibition with cyanide on chloride flux. Previous studies have found that cyanide partially inhibits chloride absorption when luminal chloride concentration is higher than that of plasma (2). This effect could be due to inhibition of active transcellular sodium chloride absorption, or inhibition of passive paracellular sodium chloride absorption secondary to cell swelling and a decrease in lateral intercellular space width. The presence of net chloride secretion with low luminal chloride concentrations provides a circumstance in which active and passive fluxes are in opposite directions, and thus the effect of cyanide can be distinguished.

The effect of cyanide on net chloride flux was examined in three simplified solutions (perfusates 5-10, Table I). In the pres-

Table V. Transepithelial Potential Difference Data

\begin{tabular}{ll}
\hline Perfusate & Potential difference \\
\hline & $m V$ \\
$1 \mathrm{~A}$ & $+1.3 \pm 0.1$ \\
$2 \mathrm{~A}$ & $+2.1 \pm 0.1$ \\
$3 \mathrm{~A}$ & $+0.6 \pm 0.1$ \\
$4 \mathrm{~A}$ & $+1.2 \pm 0.1$ \\
\end{tabular}

Values reported are corrected for liquid junction potentials. ence of a high luminal chloride concentration, addition of cyanide significantly reduced chloride absorption from $341 \pm 47$ to $194 \pm 30 \mathrm{peq} / \mathrm{mm} \cdot \mathrm{min}, P<0.025$ (perfusate $[\mathrm{Cl}]=149 \mathrm{meq} /$ liter, Table VI). These results are similar to those of Green et al. (2). The magnitude of the reduction, $147 \mathrm{peq} / \mathrm{mm} \cdot \mathrm{min}$, was similar to the magnitude of the positive $y$-intercept in Fig. 1, $131 \mathrm{peq} / \mathrm{mm} \cdot \mathrm{min}$.

Next, the effect of cyanide on net chloride flux was examined in the presence of low perfusate chloride concentrations. When perfusate chloride concentration was $104 \mathrm{meq} / \mathrm{liter}$, cyanide addition increased the rate of chloride secretion from $-151 \pm 21$ to $-254 \pm 40 \mathrm{peq} / \mathrm{mm} \cdot \mathrm{min}, P<0.05$ (Table VI). When perfusate chloride concentration was lowered further to $54 \mathrm{meq} / \mathrm{liter}$, the addition of cyanide increased the rate of chloride secretion from $-334 \pm 37$ to $-501 \pm 57 \mathrm{peq} / \mathrm{mm} \cdot \mathrm{min}, P<0.025$ (Table VI). In all three cyanide studies, the magnitude of the effect was similar to the magnitude of the positive $y$-intercept in Fig. 1. If cyanide affected chloride flux only by cell swelling and secondarily decreased chloride permeability, it would have been expected to decrease the magnitude of chloride secretion in these last two studies. Thus, cyanide affects chloride flux by inhibiting active sodium chloride absorption.

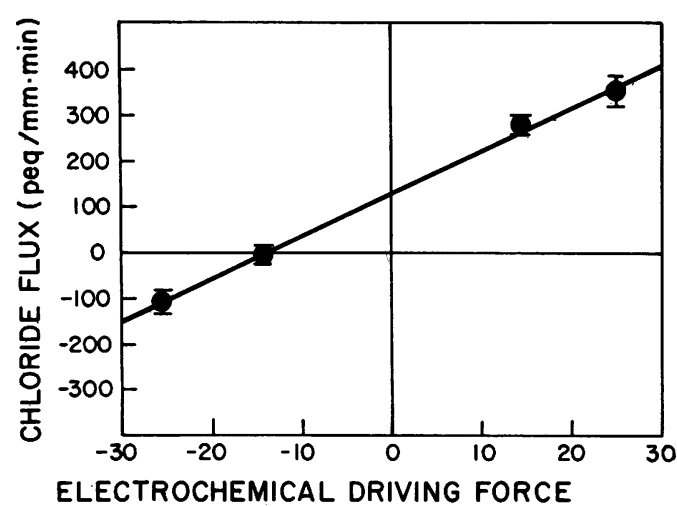

Figure 1. Chloride flux as a function of its electrochemical driving force (meq/liter). Chloride flux is plotted as a function of the electrochemical driving force for chloride in tubules perfused with solutions $1-4$ (Tables I and II). The line is defined by the equation: $J_{\mathrm{C}}=130.7$ $+9.35 D \mathrm{~F}_{\mathrm{C}} ; r=0.999 ; P<0.001$. 
Table VI. Effect of Cyanide on Net Chloride Flux

\begin{tabular}{llll}
\hline & & & \\
\cline { 2 - 4 } Perfusate & Control & Cyanide & $\Delta^{*}$ \\
\hline & peq $/ \mathrm{mm} \cdot \mathrm{min}$ & peq $/ \mathrm{mm} \cdot \mathrm{min}$ & $\mathrm{peq} / \mathrm{mm} \cdot \mathrm{min}$ \\
149 & $341 \pm 47$ & $194 \pm 30$ & $-147 \ddagger$ \\
104 & $-151 \pm 21$ & $-254 \pm 40$ & $-103 \S$ \\
54 & $-334 \pm 37$ & $-501 \pm 57$ & $-167 \ddagger$ \\
\hline
\end{tabular}

* This column lists the difference between the chloride fluxes in control and cyanide studies.

$\ddagger P<0.025$.

$\S P<0.05$.

\section{Discussion}

Chloride transport across an epithelium consists of three components, defined by the following equation:

$J_{\mathrm{Cl}}=P_{\mathrm{Cl}} D F_{\mathrm{Cl}}+\left(1-\sigma_{\mathrm{Cl}}\right) \bar{C} J_{\mathrm{v}}+J_{\mathrm{act}}$,

where $P_{\mathrm{C}}$ is the chloride permeability, $D F_{\mathrm{C}}$ the electrochemical driving force for chloride, $\sigma_{\mathrm{Cl}}$ the chloride reflection coefficient, $\bar{C}$ the mean chloride concentration, and $J_{\text {act }}$ the rate of active chloride transport. The first component of this equation represents passive diffusion, the second component solvent drag, and the third component active transport. The purpose of these studies was to examine the relative contributions of these three components to transcellular chloride flux in the rat PCT.

Chloride absorption in the rat PCT has been generally considered to be passive $(1,4,5)$. Cassola et al. (16) have recently found intracellular activity of chloride to be above electrochemical equilibrium, consistent with active transport of chloride. However, when luminal chloride was suddenly removed, the decline in intracellular chloride activity was slow (16). From this slow rate of decline the authors calculated that only a small fraction (7\% at most) of chloride absorption in the rat PCT could be transcellular.

The present studies demonstrate that passive chloride flux accounts for a significant component of chloride absorption. Chloride transport was linearly related to the electrochemical driving force, with an apparent permeability coefficient of $\mathbf{2 0 . 6}$ $\times 10^{-5} \mathrm{~cm} / \mathrm{s}$. This permeability coefficient agrees reasonably well with the tracer chloride permeability of $13.7-16.6 \times 10^{-5} \mathrm{~cm} / \mathrm{s}$ measured by Radtke et al. (17).

In addition to the passive flux of chloride, there is also a significant component of chloride absorption occurring independently of the electrochemical driving force. In Fig. 1, the positive $y$-intercept indicates that $131 \mathrm{peq} / \mathrm{mm} \cdot \mathrm{min}$ of chloride is absorbed in the absence of an electrochemical gradient. This conclusion assumes that the chloride concentration of the peritubular capillary plasma is similar to that of arterial plasma. However, for the positive intercept to be totally an artifact, the chloride concentration in the peritubular capillary would have to be $12.5 \mathrm{meq} / \mathrm{liter}$ less than that of arterial plasma. In addition, the fact that the cyanide-sensitive component of the chloride flux is equal in magnitude to the positive $y$-intercept, supports the fact that the chloride concentration of the peritubular capillary is indeed similar to that of arterial plasma. Lastly, Green et al. (2) found that addition of cyanide to the luminal fluid eliminated chloride absorption when tubules were perfused with a chloride concentration similar to that of a plasma ultrafiltrate.

This chloride absorbed in the absence of an electrochemical driving force, cannot be attributed to passive paracellular chloride diffusion, and must therefore be due to either active transcellular chloride transport or solvent drag (Eq. 10). Frömter et al. (5) also found a second flux in addition to a large chloride diffusive flux. However, these authors concluded that this remaining flux was due to solvent drag (5). These authors used a kinetic approach similar to ours (but using split droplets), and measured chloride concentration and transepithelial PD. They showed that if luminal chloride concentration is stable and in the range of plasma chloride concentration, $\bar{C} J_{\mathrm{v}}$ equals $J_{\mathrm{C}}$, and Eq. 10 reduces to

$D F_{\mathrm{Cl}}=\left(\sigma_{\mathrm{Cl}} / P_{\mathrm{Cl}}\right) \bar{C} J_{\mathrm{v}}-J_{\mathrm{act}} / P_{\mathrm{Cl}}$.

Note that this equation is only completely accurate if luminal chloride concentration is equal to peritubular chloride concentration; nevertheless, may still be a reasonable approximation at the chloride concentrations used by Frömter et al. (5). With this equation and a measured tracer chloride permeability, a plot of the electrochemical driving force for chloride $\left(D F_{\mathrm{Cl}}\right)$ vs. $\bar{C} J_{v}$ will be linear, and the $y$-intercept and slope will yield the rate of active chloride transport and the chloride reflection coefficient, respectively. Applying this approach to their split droplet data, Frömter et al. (5) found no active chloride transport and a chloride reflection coefficient of 0.5 . Applying this formulation to the results of perfusates 1-4 of the present study (to which this formulation is equally applicable) yields a linear relationship $(r=0.985)$ with a chloride reflection coefficient of $0.87 \pm 0.11$, and a rate of active transport of $102 \pm 21 \mathrm{peq} / \mathrm{mm} \cdot \mathrm{min}$ $(P<0.05$ vs. zero active transport). The reason for the discrepancy between the results of Frömter et al. (5) and those of our own is not clear, but is not related to the method of analysis, and may be related to the use of the split droplet technique in their studies.

In addition, there are two other reasons why solvent drag cannot explain the active flux we observed. First, in the cyanide studies, inhibition of active transport caused a decrease in net chloride absorption. While this was associated with a decrease in net volume absorption, it is impossible in the proximal tubule to affect chloride flux without affecting volume flux. The major question in these studies is whether primary inhibition of chloride flux led to secondary inhibition of volume flux, or whether primary inhibition of volume flux led to secondary inhibition of chloride flux. It should be noted, however, that the cyanide studies were performed with very simple solutions containing no solutes (other than $\mathrm{NaCl}$ ) that were present in sufficient amount and that have a high enough permeability to lead to the observed changes in volume flux. In that cyanide cannot primarily affect water movement, the only remaining explanations for these results are that $(a)$ cyanide inhibited active sodium transport with secondary effects on chloride transport, or $(b)$ cyanide inhibited active chloride transport. Active sodium transport could secondarily affect chloride transport in two ways. First, electrogenic sodium transport could lead to a lumen-negative PD that would drive passive chloride transport. In paired studies, we have found that inhibition of chloride transport by cyanide is not accompanied by a change in transepithelial PD (Howlin, K. J., R. J. Alpern, C. A. Berry, and F. C. Rector, Jr., unpublished observations). In agreement, Frömter (18) has found no apical membrane sodium conductance in this epithelium. 
Secondly, active sodium transport could cause volume flux that could secondarily drag chloride. However, if there is no electrogenic sodium transport in this setting, the only remaining electroneutral mechanism for sodium transport is sodium bicarbonate absorption ( $\mathrm{Na} / \mathrm{H}$ exchange). Numerous studies have found that when luminal bicarbonate concentration is low $(5$ $\mathrm{meq} / \mathrm{liter})$, the rate of net bicarbonate transport is low $(\sim 12$ $\mathrm{peq} / \mathrm{mm} \cdot \min )(6,9,10)$. The net flux of sodium bicarbonate, $24 \mathrm{posM} / \mathrm{mm} \cdot \mathrm{min}$, would lead to $<0.1 \mathrm{nl} / \mathrm{mm} \cdot \min$ of volume flux, a flux too small to lead to $100-160 \mathrm{peq} / \mathrm{mm} \cdot \mathrm{min}$ of chloride flux even if the chloride reflection coefficient were zero. Thus, there are no mechanisms that exist in the rat proximal tubule in this setting that could lead to sufficiently high rates of sodium transport to drive significant volume flux and secondarily drag the observed chloride flux.

A more direct argument against a significant rate of solvent drag relates to the results of perfusate 2 . Ideally, to prove the existence of active transport, one would like to demonstrate chloride transport in the absence of a favorable electrochemical gradient and in the absence of volume absorption. However, as mentioned above, it is difficult to demonstrate chloride transport without secondary volume absorption. In perfusate 2 , it can be seen that there was no volume absorption and no net chloride flux (Table IV). However, this occurred in the presence of a 5.6 meq/liter chloride gradient and a $+2.1 \mathrm{mV} \mathrm{PD}$, or a total electrochemical gradient of $14.3 \mathrm{meq} /$ liter favoring passive chloride secretion. Using the chloride permeability found in these studies, the predicted rate of passive chloride secretion should have been $-134 \mathrm{peq} / \mathrm{mm} \cdot \mathrm{min}$. Thus, in this setting, in which there is no volume flux and therefore no solvent drag, there is still a demonstrable active chloride absorptive flux of $134 \mathrm{peq} / \mathrm{mm} \cdot \mathrm{min}$. Thus, active transcellular chloride flux does occur in the rat PCT. While solvent drag may contribute somewhat to the slope and the $y$-intercept of the present results, it is not a major contribution.

The demonstration of active chloride transport in the present studies is in contrast to the failure of Neumann and Rector (1), Green et al. (2), and Jacobson (3) (superficial PCT) to find any active transport of chloride in studies in which chloride concentration gradients were prevented by replacing $20 \mathrm{meq} / \mathrm{liter}$ bicarbonate with nonadsorbable anions (cyclamate, sulfate, and methylsulfate). One possible explanation for this discrepancy is that the chloride transport mechanism might have been inhibited by the anions used to replace bicarbonate (1-3). However, at present there is no data to support this thesis.

The presence of active transport agrees with the findings of Cassola et al. (16) that cell chloride concentration is above electrochemical equilibrium. However, the magnitude of active chloride absorption observed in the present studies far exceeds the value calculated by these authors from the rate of decline of intracellular chloride activity when luminal chloride was suddenly removed. Their calculations, however, assumed that the rate constant for the exit of chloride from the cell did not change upon removal of luminal chloride. If, in fact, the chloride permeability of the luminal and basolateral membranes were decreased in a regulatory fashion, perhaps to preserve cell volume, then the rate of transcellular chloride transport would be grossly underestimated by this approach. At present it is not known whether such a regulatory mechanism exists in this epithelium.

When PCT were perfused with a high chloride solution resembling late proximal tubular fluid, chloride absorption was $\sim 350 \mathrm{peq} / \mathrm{mm} \cdot \mathrm{min}$. The active transport of $131 \mathrm{peq} / \mathrm{mm} \cdot \mathrm{min}$ would represent $35-40 \%$ of the total chloride transported. This estimate of the active component of chloride transport agrees well with the results of other studies in the rat PCT. Chantrelle et al. (7) perfused lumen and peritubular capillaries of PCT with identical high chloride solutions resembling late proximal tubular fluid. In the absence of chemical gradients, volume absorption was $0.91 \mathrm{nl} / \mathrm{mm} \cdot \mathrm{min}$, which would represent an active transport-dependent chloride flux of $137 \mathrm{peq} / \mathrm{mm} \cdot \mathrm{min}$ (7). This component of absorption was reduced to zero by inhibition of the Na,K-ATPase. Although these authors did not measure PD, and thus could not eliminate passive paracellular chloride transport dependent on active transcellular sodium transport, the present study shows that this active transport-dependent flux represents transcellular chloride absorption.

Cogan and Rector (19), in free-flow micropuncture studies, analyzed chloride flux as a function of the end-proximal luminal chloride concentration gradient, and found that chloride flux increased linearly with increasing concentration gradient. Using an estimated transepithelial PD, the chloride permeability coefficient calculated from the slope of their relationship was 15.4 $\times 10^{-5} \mathrm{~cm} / \mathrm{s}$ (19). This value is close to ours, but may be smaller because end-proximal chloride concentration was used instead of mean luminal chloride concentration. In addition, at zero concentration gradient, there was an absorptive flux of $\sim 600$ $\mathrm{peq} / \mathrm{min}$ in PCT $4.5-5.0 \mathrm{~mm}$ in length (19). Thus, in free-flow tubules the estimated active component of chloride absorption is $120-135 \mathrm{peq} / \mathrm{mm} \cdot \mathrm{min}$, a value very close to that obtained in the present studies.

In isolated perfused rabbit PCT, Berry (8) and Baum and Berry (20) have demonstrated a significant component of active chloride transport that approximates $40-60 \%$ of total chloride absorption. In addition, in their studies, the active component of chloride transport was clearly electroneutral. In tubules perfused with a high chloride solution resembling late proximal tubular fluid and bathed with an ultrafiltrate-like solution, inhibition of active chloride transport did not lead to a change in the transepithelial PD $(8,20)$. When tubules were perfused and bathed in symmetrical high chloride solutions, the transepithelial PD was zero despite significant chloride transport (20). These results clearly establish active, transcellular, electroneutral chloride transport in the rabbit PCT.

The mechanism of this electroneutral transcellular chloride transport is not known. However, it is known that the active step involves cellular uptake across the luminal membrane (16), and since it is inhibited by inhibition of the Na,K-ATPase (7, 20 ), the process must be coupled directly or indirectly to active sodium transport.

In summary, the present results demonstrate two components of transepithelial chloride flux. The first is passive, paracellular, and defined by a chloride permeability coefficient of $20.6 \times 10^{-5} \mathrm{~cm} / \mathrm{s}$. The second is an active, transcellular chloride flux of $100-160 \mathrm{peq} / \mathrm{mm} \cdot \mathrm{min}$, which is inhibited by cyanide.

\section{Acknowledgments}

The authors gratefully acknowledge the continued support of Floyd C. Rector, Jr., and the secretarial assistance of Gracie Parrilla.

This study was supported by grants AM-01229 and AM-27045 from the National Institute of Arthritis, Diabetes, and Digestive and Kidney Diseases.

\section{References}

1. Neumann, K. H., and F. C. Rector, Jr. 1976. Mechanism of $\mathrm{NaCl}$ and water reabsorption in the proximal convoluted tubule of rat kidney: role of chloride concentration gradients. J. Clin. Invest. 58:1110-1118. 
2. Green, R., J. H. V. Bishop, and G. Giebisch. 1979. Ionic requirements of proximal tubular sodium transport. III. Selective luminal anion substitution. Am. J. Physiol. 236(Renal Fluid Electrolyte Physiol. 5): F268-F277.

3. Jacobson, H. R. 1979. Characteristics of volume reabsorption in rabbit superficial and juxtamedullary proximal convoluted tubules. $J$. Clin. Invest. 63:410-418.

4. Chantrelle, B., M. G. Cogan, and F. C. Rector, Jr. 1979. Determinants of volume reabsorption in rat proximal convoluted tubules (PCT). Kidney Int. 16:809. (Abstr.)

5. Frömter, E., G. Rumrich, and K. J. Ullich. 1973. Phenomenologic description of $\mathrm{Na}^{+}, \mathrm{Cl}^{-}$, and $\mathrm{HCO}_{3}^{-}$absorption from proximal tubules of the rat kidney. Pflügers Arch. Eur. J. Physiol. 343:189-220.

6. Lucci, M. S., and D. G. Warnock. 1979. Effects of anion-transport inhibitors on $\mathrm{NaCl}$ reabsorption in the rat superficial proximal convoluted tubule. J. Clin. Invest. 64:570-579.

7. Chantrelle, B., M. G. Cogan, and F. C. Rector, Jr. 1985. Active and passive components of $\mathrm{NaCl}$ absorption in the proximal convoluted tubule of the rat kidney. Miner. Electrolyte Metab. In press.

8. Berry, C. A. 1983. Lack of effect of peritubular protein on passive $\mathrm{NaCl}$ transport in the rabbit proximal tubule. J. Clin. Invest. 71:268281.

9. Alpern, R. J., M. G. Cogan, and F. C. Rector, Jr. 1982. Effect of luminal bicarbonate concentration on proximal acidification in the rat. Am. J. Physiol. 243(Renal Fluid Electrolyte Physiol. 12):F53-F59.

10. Alpern, R. J. 1984. Bicarbonate-water interactions in the rat proximal convoluted tubule: an effect of volume flux on active proton secretion. J. Gen. Physiol. 84:753-770.

11. Ramsay, J. A., R. H. J. Brown, and P. C. Croghan. 1955. Elec- trometric titration of chloride in small volumes. J. Exp. Biol. 32:822829.

12. Preisig, P. A. 1983. Transepithelial pathway of osmotic water flow in the rat proximal convoluted tubule. Ph.D. Thesis. University of California, San Francisco.

13. Barratt, L. J., F. C. Rector, Jr., J. P. Kokko, and D. W. Seldin. 1974. Factors governing the transepithelial potential difference across the proximal tubule of the rat kidney. J. Clin. Invest. 53:454-464.

14. Bomsztyk, K., and F. S. Wright. 1982. Effects of transepithelial fluid flux on transepithelial voltage and transport of calcium, sodium, chloride, and potassium by renal proximal tubule. Kidney Int. 21:269. (Abstr.)

15. Rector, F. C., Jr., M. Martinez-Maldonado, F. P. Brunner, and D. W. Seldin. 1966. Evidence for passive reabsorption of $\mathrm{NaCl}$ in proximal tubule of rat kidney. J. Clin. Invest. 45:1060. (Abstr.)

16. Cassola, A. C., M. Mollenhauer, and E. Frömter. 1983. The intracellular chloride activity of rat kidney proximal tubular cells. Pflügers Arch. Eur. J. Physiol. 399:258-265.

17. Radtke, H. W., G. Rumrich, S. Kloss, and K. J. Ullrich. 1971. Influence of luminal diameter and flow velocity on the isotonic fluid absorption and ${ }^{36} \mathrm{Cl}$ permeability of the proximal convolution of the rat kidney. Pflügers Arch. Eur. J. Physiol. 324:288-296.

18. Frömter, E. 1977. Magnitude and significance of the paracellular shunt path in rat kidney proximal tubule. Excerpta Med. Int. Congr. Ser. 391:393-405.

19. Cogan, M. G., and F. C. Rector, Jr. 1982. Proximal reabsorption during metabolic acidosis in the rat. Am. J. Physiol. 242(Renal Fluid Electrolyte Physiol. 11):F499-F507.

20. Baum, M., and C. A. Berry. 1984. Evidence for neutral transcellular $\mathrm{NaCl}$ transport and neutral basolateral chloride exit in the rabbit proximal convoluted tubule. J. Clin. Invest. 74:205-211. 